\title{
Resumen de tesis: “La alpargata en el espacio público. Los efectos de la política lencinista en el espacio público mendocino (1918-1928)"1
}

\author{
Natalia Mabel Luis \\ (Instituto de Ciencias Humanas, Sociales y Ambientales, CONICET, \\ Argentina) \\ nluis@mendoza-conicet.gob.ar
}

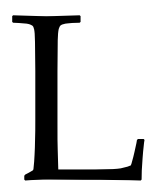
a tesis doctoral, cuyo resumen se presenta a continuación, es producto de una investigación histórica que articula perspectivas de la Nueva Historia Política ${ }^{2}$ y de la Historia Urbana. ${ }^{3}$ Se considera la ciudad como un documento que registra en lo material, en lo funcional y en lo simbólico lo que las políticas enuncian sobre el espacio.

En relación con el periodo de estudio es importante señalar que entre fines del siglo XIX y comienzos del XX se asistió en Latinoamérica a una ampliación de la esfera pública y a una modificación de la práctica electoral y de la forma de hacer política. En Argentina fue particularmente importante la sanción de la ley Sáenz Peña en 1912 mediante la cual se garantizó la representación de la minoría y se posibilitó el ascenso del Partido Radical al gobierno nacional en 1916. En Mendoza triunfó, en enero de 1918, el radicalismo lencinista, iniciando un periodo de 10 años. Estos gobiernos de tinte personalista (especialmente los dos primeros) esgrimieron un discurso antioligárquico y propusieron medidas destinadas a mejorar la calidad de vida de la población, especialmente de los sectores medio y bajo de la sociedad.

El periodo fue inestable. Hubo tres gobernaciones y cuatro intervenciones federales, lo que generó escasa continuidad de las propuestas políticas que se encontraban en marcha. Ello, sumado a la inestabilidad económica (durante el periodo se alternó una

\footnotetext{
${ }^{1}$ Tesis de Doctorado en Historia defendida el 8 de mayo de 2019 en la Facultad de Filosofía y Letras de la Universidad Nacional de Cuyo, dirigida por la Dra. Arq. Silvia Augusta Cirvini (INCIHUSA-CONICET) y codirigida por la Dra. Eugenia Molina (IDEHESI-CONICET/ UNCUYO). La misma fue financiada mediante Beca Doctoral de CONICET 2014-2019. El jurado evaluador estuvo compuesto por el Dr. Diego Roldán (Universidad de Rosario/CONICET); la Dra. Patricia Barrio (UNCuyo/CONICET) y la Dra. Valeria Caroglio (UNCuyo). Calificación: Sobresaliente con mención de Honor.

${ }^{2}$ En la Nueva Historia Política se ensancha la naturaleza de lo político, abarcando nuevos actores, fenómenos y lenguaje (Barriera, 2002, p. 173).

${ }_{3}^{3}$ Principalmente se consideró estudios referentes a las transformaciones urbanas de fines del siglo XIX y comienzos de XX en Argentina (Gorelik, 1998; 2008 y Roldán, 2012; 2016) y en Mendoza (Ponte, 1999; Cirvini, 1989; 1999 y Raffa, 2007), entre otros.
} 
época de auge, a la cual siguió una importante crisis financiera) hizo que muchos de los planes ideados por los dirigentes no pudieran concretarse.

Varios autores han analizado las gobernaciones lencinistas (Rodríguez, 1979; Lacoste, 1995; Richard Jorba, 2011; 2016) y hay estudios referentes a las transformaciones urbanas del periodo (Raffa, 2005 y 2011; Cremaschi, 2012). Sin embargo, la historiografía no se ha detenido a profundizar sobre la infraestructura de servicios durante ese lapso temporal.

En esta tesis se propone avanzar sobre esa temática vacante. Se analizan las vinculaciones entre los procesos socio-políticos y los espaciales, considerando particularmente las políticas propuestas e implementadas en relación con la infraestructura básica de servicios (estado sanitario, agua potable y red cloacal), la infraestructura habitacional y la infraestructura vial.

La investigación da cuenta de una problematización del espacio público, considerado como el producto de una articulación entre forma y política (Gorelik, 1998, pp. 19-21), un concepto situado históricamente, "producido" a partir de diferentes políticas gubernamentales y prácticas sociales, pero, a su vez, "productor" de participación o diferenciación/ segregación social (Roldán, 2016, p. 9). Se sostiene que durante el periodo lencinista se planteó la necesidad de complejizar la estructura y organización de este ámbito, a los fines de propiciar una mayor democratización del espacio y de los servicios, que fueron entonces apropiados por actores sociales hasta el momento marginados de ellos.

Esto permitió profundizar la mirada sobre las vinculaciones entre técnica y política, ${ }^{4}$ las cuales atravesaron esa referida reformulación. Los profesionales comenzaron a tener un espacio específico de desarrollo en la administración pública, con una creciente valorización de su labor. Asimismo, desde el Estado hubo un esfuerzo por reglamentar el ejercicio profesional. Un ejemplo de esto último es la Reforma de la ley sanitaria, en 1927, que reguló las actividades curativas o también el proyecto de ley no sancionado sobre regulación del ejercicio de la arquitectura, ingeniería y agrimensura, de 1922, que proponía la obligatoriedad de contratar profesionales para la ejecución de obras públicas.

Para realizar el estudio se consultaron diversos repositorios documentales y se entrecruzaron diferentes fuentes primarias. Documentos gubernamentales de la esfera del Poder Ejecutivo, tales como decretos, Memorias del Ministerio de Obras Públicas, Memoria de la Dirección General de Salubridad (Archivo Histórico de Mendoza y Biblioteca Pública General San Martín). Documentos legislativos: actas, diarios de sesiones legislativas y proyectos de ley (Archivo de la Legislatura de Mendoza). A partir de ellos fue factible conocer no solo las medidas implementadas, sino el ideario y las propuestas de los gobiernos lencinistas, eje central de análisis de esta tesis. Además, se consultó prensa de diverso signo político: La Palabra, Los Andes, La Tarde y El Socialista (Hemeroteca de la Biblioteca Pública General San Martín). Del mismo modo, se

${ }^{4}$ Cfr. Plotkin y Zimmerman, 2012a y 2012b. Para el caso de Mendoza: Rodríguez Vázquez y Raffa, 2016. 
utilizaron mapas y gráficos de obras sanitarias para facilitar un recurso gráfico sobre la extensión de los servicios (Archivo de la empresa Aguas Mendocinas). Por último, se consultaron Anuarios Estadísticos (Dirección General de Estadísticas de Mendoza), para, además de analizar los proyectos, dar cuenta de lo que efectivamente se realizó y conocer a cuánta población alcanzó.

La tesis se organiza en cuatro capítulos, precedidos por una introducción, y finaliza con una serie de reflexiones que dejan el camino abierto a nuevos interrogantes para seguir investigando en posteriores instancias postdoctorales. Se adjunta luego un apéndice documental que profundiza sobre las fuentes indagadas.

En el primer capítulo, se realiza una descripción del contexto sociopolítico y económico de las gobernaciones lencinistas y se analiza de manera particular los proyectos de ley y las reglamentaciones establecidas sobre el ejercicio profesional.

El capítulo dos, por su parte, analiza el estado sanitario general de Mendoza durante el periodo lencinista, haciendo referencia al sistema asistencial de salud (obras públicas, medidas preventivas y paliativas) y a la profesionalización de las actividades curativas; además, de manera particular, se analiza la extensión de los servicios de agua potable y red cloacal, así como también las propuestas en torno al recurso de agua mineral Villavicencio.

La implementación de medidas preventivas y paliativas por la Dirección de Salubridad durante el periodo estudiado trajo aparejada una disminución del porcentaje de enfermos y recayó en una mengua significativa de la tasa de mortalidad provincial. Se pudo observar cómo el desarrollo de las estadísticas y el avance del conocimiento médico científico hicieron posible que el Estado comenzara a proyectar políticas públicas que mejoraran la calidad de vida de la población y previnieran situaciones de crisis anteriormente vividas. Entre otras medidas, los dirigentes lencinistas propiciaron, y lograron con relativo éxito, mayor accesibilidad a servicios sanitarios antes reservados a la élite.

En el capítulo tres se presenta un análisis de las condiciones habitacionales de Mendoza, haciendo hincapié, por un lado, en los planes de vivienda popular propuestos por los dirigentes, y por el otro, en las características constructivas y peculiaridades propias de la región. Fue posible observar cómo, en un contexto signado por la instalación del debate sobre la vivienda como un ámbito en el que debía intervenir el Estado, y ante la necesidad de resolver el problema habitacional, los gobiernos lencinistas propusieron diferentes planes de vivienda popular. El incremento de la intervención estatal en materia habitacional estuvo relacionado, además, a la profesionalización de ciertas disciplinas y al surgimiento de expertos en áreas técnicas que cumplieron un rol fundamental en el planeamiento y ejecución de las obras.

En el cuarto y último capítulo se considera el desarrollo de las vías comunicacionales y los medios de transporte. Se analizan ambos aspectos junto con la transformación urbana vinculada a ellos. Los dirigentes plantearon crear nuevas vías comunicacionales y ampliar las existentes a fin de conectar lugares e integrar zonas periféricas, 
favoreciendo de esa manera una mayor integración territorial. Además, plantearon extender el servicio de transporte para facilitar el arribo de los sectores de clase media y popular a lugares antes inaccesibles, propiciando con ello la democratización del servicio. Por último, el crecimiento en cantidad y densidad del parque automotor en la década del '20 en Mendoza generó, por un lado, una ampliación de las actividades económicas (tanto a partir de la producción local de combustible como por las obras de infraestructuras requeridas), y, por otro, definió una esfera específica de actuación para la intervención estatal. Esta no solo debió hacer frente a los problemas que trajo aparejados a la trama de vías comunicacionales existentes, estimulando su ampliación y complejización, sino también a los comportamientos vinculados a esta cuestión, los cuales debieron comenzar a ser disciplinados y vigilados a partir de una normativa particular.

De esa manera, a lo largo de los capítulos, la investigación da cuenta de una problematización del espacio público. Se pudo constatar que efectivamente se planteó la necesidad de complejizar la estructura y organización del espacio a los fines de ofrecer servicios y accesos a recursos, anteriormente concentrados en ciertos ámbitos y sectores, a más amplios grupos sociales. No solo se proyectó una ampliación de las infraestructuras referidas en relación con la mayor cobertura en su aspecto geográfico, sino que también ello implicó una reformulación sobre cuál era el deber del Estado en vinculación con ello.

La ampliación de las funciones del Estado en diversos ámbitos (condiciones habitacionales, infraestructura de servicios sanitarios, y de vías comunicacionales y de transporte) durante el periodo se desarrolló de la mano de la reglamentación de la práctica profesional y de un incremento del número de especialistas en la burocracia estatal. Este proceso, si bien había comenzado con anterioridad, se profundizó durante el periodo lencinista y continuó desarrollándose en la década del ‘30.

Por último, se pudo constatar que el espacio público tuvo modificaciones concretas relativas a las prácticas de uso y apropiación, como consecuencia de las políticas propuestas e implementadas por el lencinismo en el poder. Tanto la modificación en los procesos de apropiación del mismo, como el incremento de la movilidad dentro de la ciudad y la legitimación en el disfrute de los bienes públicos significaron una mejora, en algunos casos material y en otros simbólica, de la vida de los sectores medios y populares de Mendoza.

Las consideraciones finales de la investigación visibilizan la oportunidad de profundizar esta línea de investigación en la etapa posdoctoral ampliando geográficamente el objeto de estudio y complejizándolo a partir de la incorporación de otras variables, analizando, por ejemplo, las modificaciones proyectadas y ejecutadas en las vías de comunicación de Mendoza con otras provincias (rutas interprovinciales) y con Chile (ruta internacional). Este tema está íntimamente relacionado con el despliegue 
de la actividad turística y sus transformaciones a partir del uso de los transportes automóviles.

\section{Referencias bibliográficas}

Barriera, D. (2002). Por el camino de la historia política: hacia una historia política configuracional. SECUENCIA. Revista de Historia y Ciencias Sociales, 53, 163-196.

Plotkin, M. y Zimmermann, E. (2012a). Los saberes del Estado. Construcción de elites técnicas estatales en la Argentina, siglos XIX y XX. Buenos Aires: Edhasa.

Plotkin, M. y Zimmermann, E. (2012b). Las prácticas del Estado. Política, sociedad y elites estatales en la Argentina del siglo XX. Buenos Aires: Edhasa.

Cirvini, S. (1989). El ambiente urbano en Mendoza a fines del siglo XIX. La higiene social como herramienta del proyecto utópico del orden. En M. Rodríguez Lapuente y $\mathrm{H}$. Cerutti Guldberg (Comps.). Arturo Roig. Filósofo e historia de las ideas (pp. 107-143). Guadalajara: Universidad de México.

Cirvini, S. (1999). El espacio urbano moderno. La función utópica en el discurso sarmientino. Revista Historia de América IPGH, 122, 109-126.

Cremaschi, V. (2012). Proyectos urbanos difundidos por la presa durante los gobiernos lencinistas, Mendoza. Visiones sobre la vivienda para la chusma de alpargatas. Revista Historia de América, 147, 57-75.

Gorelik, A. (1998). La grilla y el parque. Espacio público y cultura urbana en Buenos Aires, 1887-1936. Buenos Aires: Universidad Nacional de Quilmes.

Gorelik, A. (2008). El romance del espacio público. Alteridades, 36 (18), 33-45.

Lacoste, P. (1995). La Unión Cívica Radical en Mendoza y en la Argentina, 1890-1946. Mendoza: Ediciones Culturales.

Ponte, R. (1999). La fragilidad de la memoria. Representaciones, prensa y poder de una ciudad latinoamericana en tiempos del modernismo. Mendoza, 1885/1910. Mendoza: Fundación CRICYT.

Raffa, C. (2005). Proyectos clásicos para una Mendoza imaginada: acerca del concurso para el Palacio de Gobierno en la Plaza Independencia, 1927. Anales, 37-38, 143-167.

Raffa, (2007). El imaginario sanitario en Mendoza a fines del siglo XIX: Obras de higiene y salubridad durante la intendencia de Luis Lagomaggiore (1884-1888). Revista de Historia Social y de las Mentalidades, XI (2), 173-200.

Raffa, C. (2011). El espacio público como lugar de legitimación política: sobre las disputas entre Emilio Civit y José Lencinas, Mendoza 1910 y 1918. Prohistoria, 15, 6-17

Richard Jorba, R. (2011). Los gobiernos radicales de los Lencinas en Mendoza. Salud pública y vivienda popular, 1918-1924. Rupturas y continuidades con el orden conservador. Avances del Cesor, 9, 31-62.

Richard Jorba, R. (2016). El Departamento Provincial del Trabajo durante la década lencinista: participación de una agencia estatal en el diseño y aplicación de políticas sociales. Mendoza, 1918-1928. En F. Rodríguez Vázquez y C. Raffa (Coords.). Profesionalizando un Estado provincial: Mendoza, 1890-1955 (pp. 43-83). Mendoza: Universidad Nacional de Cuyo-Secretaría de Ciencia, Técnica y Posgrado.

Rodríguez Vázquez, F. y Raffa, C. (Coords). (2016). Profesionalizando un Estado provincial: Mendoza, 1890-1955. Mendoza: Universidad Nacional de Cuyo-Secretaría de Ciencia, Técnica y Posgrado. 
Rodríguez, C. (1979). Lencinas y Cantoni. El populismo cuyano en tiempos de Yrigoyen. Buenos Aires: Editorial Belgrano.

Roldán, D. (2012). La invención de las masas: ciudad, cuerpos y culturas: Rosario, 1910-1945. La Plata: Universidad Nacional de La Plata.

Roldán, D. (2016). Prólogo. "Pensar la segregación urbana". En J. Perren. Segregación residencial en las ciudades intermedias argentinas. El caso de Neuquén (1980-1991) (pp. 912). Neuquén: EDUCO-CONICET.

Para citar este artículo:

Luis, Natalia Mabel (2020). Resumen de Tesis: “La alpargata en el espacio público. Los efectos de la política lencinista en el espacio público mendocino (1918-1928)". Anuario de la Escuela de Historia Virtual, 18, 256-261. 